\title{
Informatization of Shipbuilding Enterprises and Countermeasures
}

\author{
Jishen Zhou \\ China Ship Development and Design Center \\ Wuhan, China \\ e-mail: zhou_jishen@126.com
}

\author{
XiaoFang $\mathrm{Zu}^{1,2}$ \\ ${ }^{1}$ School of Geography and Environment, Jiangxi \\ Normal University, Nanchang, China \\ ${ }^{2}$ Key Laboratory of Poyang Lake Wetland and \\ Watershed Research, Ministry of Education, Nanchang, \\ China \\ zxf_0412@126.com
}

\begin{abstract}
Informatization of shipbuilding enterprises is the only way to achieve modernization for the shipping companies in line with international standards. This paper puts forward some typical problems existing in the process of shipbuilding enterprises informatization in our country by combining the status quo of shipbuilding enterprises informatization at home and abroad, and in view of the problems, this paper put forward the countermeasure and the suggestion on the basis of summarizing the predecessors' research achievements. Finally, this paper provides the informatization platform reference model and processes for the production design of small and medium-sized shipbuilding enterprises in order to be of a certain practical significance for China's shipbuilding enterprises informatization.
\end{abstract}

Keywords-Informationization Countermeasure; Shipping; Enterprises

\section{INTRODUCTION}

With the development of network and communication technology, "digital shipbuilding" has become the target of world shipbuilding industry. Our country is shipbuilding leader; shipbuilding production has been the third after South Korea, Japan for ten years. Shipbuilding industry is one of important pillar industries for export in our country, and it has a pivotal position. But compared with countries such as Japan, South Korea, the shipbuilding enterprises in China have a big shortage on the whole. In order to promote the overall competitiveness of China's shipbuilding industry, China has put forward the revitalization plan of shipbuilding industry, advocate the modern shipbuilding mode of "digital shipbuilding”.

"Digital shipbuilding" requires the shipbuilding enterprises should change the design and operation mode and management mode of shipbuilding industry with the informationization way, promote modernization of shipbuilding with informationization. Informatization not only can help shipbuilding enterprises to build ships of higher performance with lower costs, but also improve the ability of the enterprises to adapt to market changes faster, to help enterprises to improve the relationship with the environment, and more importantly, the inherent characteristics of informatization itself can make the target of constructing service-type shipbuilding industry become possible.

\section{SITUATION AT HOME AND ABROAD}

In the face of the challenges of the knowledge-based economy in the 21st century, the shipbuilding industry with capital, technology, labor-intension should further enhance the technological innovation capacity, realize shipbuilding management modernization, we also must strengthen the construction of enterprise informatization. How to do a good job in the construction of enterprises informatization, we cannot jump to success, it is needed to be combined with the present situation of the enterprise informatization, first, plan the information resource, and then disperse development system. In the process of information resource planning, great attention should be paid to the division of function domain, control the scope of the plan.

Researchers evaluated the key backbone shipyards with the internationally accepted 68 elements 340 standards, found the comprehensive gap between the shipbuilding manufacturing industry in China and the world's advanced level was 15 years, among them, the gap in precision control technology was 15 years, the gap between organization and management system was 18 years, the gap in information technology applications was 19 years. The design and manufacturing process of shipbuilding product is complex, for the designs of different products, the manufacturing processes are not identical, the supporting enterprises amount to more than one thousand, parts and components account to more than one million, informatization construction for each ship has its own characteristics, and cannot be simply repeated or replicated, which is doomed the difficulty of informatiozation construction.

Chinese shipbuilding industry is one of the earliest applied computer industries in our country manufacturing industry, in 1965 it began the research and application of the shipbuilding design calculations and shipbuilding manufacturing CAM, for nearly 50 years, shipbuilding computer application has made great improvement. In the past, shipbuilding is like making the same clothes; it is needed to draw, loft, and cut. Shipyards often have a big sample stage like a basketball court, workers cut plates and tens of thousands of steel pipes in the sample stage. They sampled and installed pipes back and forth on more than ten 
- storey ships and workshops, workers are not only painstaking, the amount of rework is large, it is difficult to guarantee quality, material waste is really amazing. With the support of informatization platform, the cutting machine in the sub-workshop can accurately install steel plate into the assembly lines, automatic welding system replaces the worker's high-intensity operations. At present, the main backbone shipbuilding manufacturing enterprises have widely used computer-aided design (CAD) and computeraided manufacturing (CAM) system, which greatly reduces the labor intensity of shipbuilding designers and front-line workers and shortens the shipbuilding cycle, improves the quality of shipbuilding, the shipbuilding output of the main shipyards increased more than 10 times.

Many domestic enterprises have introduced some design systems with good integration level, but most just solved the work of "rejection drawing board", and did not realize the integration in the whole process. Due to the characteristics of shipbuilding manufacturing industry and other reasons, shipbuilding informatization falls behind the applications of certain manufacturing industry on the whole, and there is a relatively large gap compared with some developed and advanced shipbuilding countries.

As China's national conditions are inconsistent with those of foreign shipbuilding industry, software in the foreign shipbuilding industry is used for commercial interests and technological security; it is difficult for secondary development in China. General CAD / CAM software and management software is difficult to adapt to the needs of shipbuilding enterprises. For the ship manufacturing enterprises, all kinds of hardware and software resources cannot be shared; it is difficult to make an optimized decision more scientific for the company management, purchasing, production, quality, cost, resulting in production and business activities of enterprises cannot reach the purposes of precise configuration of each production factor, so that the shipbuilding cycle lengthened, accordingly, the shipbuilding costs will increase exponentially.

The enterprises on our shipbuilding industry chain are relatively dispersed, such as Hudong Zhonghua, 611, Guangzhou Shipyard International, Jiangnan Group, the enterprises with strong ship software development ability haven't formed concerted efforts because of the mechanism, the results are not shared. Researchers suggested authorities should integrate the information technology, human resources advantages in different regions, and in different units, conduct collective research and independent innovation, work according to one's ability, make good use of one own ability and finally form a shipbuilding industry information system with Chinese enterprise features. Cooperate with many shipbuilding enterprises with their own characteristics under the idea of brainstorming, and pooling the wisdom and efforts of everyone, carry out productive collaboration, it is needed to solve a number of existing problems in shipbuilding enterprises and to develop effective long-term cooperation mechanism, these problems need to be solved emphasized, separately.

\section{PROBlEMS EXISTING IN THE CONSTRUCTION OF SHIPPING INFORMATIONIZATION}

In the implementation process of informationization, the shipbuilding enterprises often encounter many difficulties technically and managerially. Only through realizing the difficulties, breaking through the bottleneck and finding the solutions, the enterprises can be on a wide "Fast Track" of the informationization. The development of informationization technology itself has been expounded in a large number of literatures, so hereby it will not be repeated in this paper. Through combining with the characteristics of the shipping industry, this paper makes a brief analysis of shipping informationization.

\section{A. Attaching great importance to the construction of conditions, and ignoring the cultivation of \\ talents.Maintaining the Integrity of the Specifications}

Because of its industrial characteristics, the shipbuilding enterprises are usually the state-owned enterprises, and their various funds are invested by the government of China. Generally speaking, physical investment such as equipment and facilities is more effective and faster than the talent investment, so the shipbuilding enterprises purchase the equipment in a large quantity. In the condition of a certain fund, the cultivation of talents is necessarily ignored. The quantity of some enterprises purchasing advanced workstations and software exceeds that of research personnel, so the computers purchased two years ago have not been put into use, and the software in use is grasped at the low level of application. Taking the structural strength analysis an example, the function enhanced in the new software of structural analysis lies in the interaction between the comprehensive integrated analysis and think, but this aspect in the industry still rests on the application of finite element basic module. The lack of talents and the development imbalance of hardware construction of shipping informationization will continually influence the development of shipbuilding enterprises for some time to come.

\section{B. Attaching great importance to the monographic research, and ignoring the top-level design.}

Take the shipping main and auxiliary equipment industry as an example. The main and auxiliary equipment is involved in a variety of disciplines, such as thermodynamics, heat and mass transfer theory, frictional wear, vibration noise and automatic control, with complex structure and wide collaboration scope. The development of complex comprehensive products needs to start with market demand. According to the characteristics of product technology and production characteristics, various aspects are planned, such as R\&D-production-service system as well as the generation, use and storage of related information. In China, the existing finite element software, modal analysis software and hydrodynamic force analysis software, however, may come from different departments of research and development. When the software is integrated, the information isolated island leads to the poor software 
data sharing, affecting the consistency and integrity of data, so manual intervention is often required, and the software cannot realize the value maximization. The deficiency of initial planning is likely to become an obstacle to the next stage of development.

\section{Attaching great importance to the software purchase, and ignoring the establishment of knowledge bases.}

Usually, conventional software does not include the knowledge and experience required by the shipbuilding enterprises. The foreign shipbuilding enterprises started to do the informationization early, in the development process, the enterprises constantly insist on accumulating and sorting out the knowledge and experiences (including text, drawings, diagrams, etc.) for a long time. Ultimately, they are used in the process of construction of shipbuilding informationization, forming enormous data repositories (including successful experience and failure lessons), and are regarded as a special skill. The establishment of a knowledge base in the shipbuilding enterprises also creates the conditions for the talent flow, conducive to integrating the knowledge of staff from different enterprises. The difference between commercial software and hardware configurations of shipbuilding counterparts can be quickly narrowed through capital investment in China, but the knowledge and talents accumulated by the enterprises cannot be purchased. In China, the knowledge and experiences forming in the shipbuilding are usually mastered by individuals. For this purpose, it is very necessary for the shipbuilding enterprises to process and integrated the knowledge and experiences dispersed in the brains of technicians and to establish their own knowledge bases adapting to national conditions and enterprise situations through information technology in the construction process of shipping informationization.

\section{THINKING ABOUT COUNTERMEASURES}

In the face of surging waves of informationization construction, China is meeting severe challenges and rare development opportunities. So the domestic shipbuilding enterprises must grasp the initiative, rely on service ability of each enterprise on the industrial chain, make long-term planning, and implement step by step, to improve the efficiency. Aiming at the current dilemma of Informationization construction of shipbuilding enterprises in China, the author puts forward some suggestions in combination with the researches by some domestic scholars:

\section{A. The construction of shipping informationization should adhere to the top-level design.}

In order to ensure the rapid, sustainable and steady development of informationization construction, the toplevel design is very important. There are two problems urgently needing to be solved for the scientific top-level design: the first one is to study and establish the shipping informationization architecture; the second one is to study and establish the evaluation index system of shipping informationization level. In the top-level design, the development planning should be considered, and what more important is to make careful analysis, research and demonstration of the target and process of shipping informationization. The main content of the top-level design includes: the target and approach of informationization construction, organizational leadership, theoretical research, system development, talents cultivation, etc.

The top-level design for the informationization of shipbuilding enterprises should focus on technological innovation and practical application. The development of information technology must start from the planning. Without the creation of conditions in the overall planning and specific application target, the results the informationization deserves will not be obtained. When it comes to the planning, the parallel and alternation procedure of the old and new management system should be considered in the process of informationization. The process of informationization is not only a process of innovative development, but also a working process where the original knowledge and skills are incorporated and work in the new system.

In addition, the factors such as China's national conditions, scientific and technological strength should be fully considered in the top-level design, to ensure that the construction of shipping informationization can be developed coordinately, stably, healthily and efficiently, in the right direction, in a planned way and in an emphasized manner

\section{B. The construction of shipping informationization must}

take priority to the policies and regulations, standard specification.

The policies, regulations and standard specification of shipping informationization are an important part of construction of shipping informationalization, and is the fundamental guarantee to keep the rapid, sustainable, orderly and healthy development of shipping informationization. The policies and regulations of shipping informationization are applied to regulate and coordinate the relationship between the elements of shipping informationization, and involved in each department, several links and complex technology, so it is imperative to establish a set of scientific, advanced, accurate and practical policies, regulations and standard specifications with good maneuverability.

At present, China has formulated and released a series of informationization policies, regulations and standard specification, providing an important reference for the construction of policies, regulations and standard specification of shipping informationization. The policies and regulations of shipping informationization should not only comply with the requirements relevant national policies and regulations, but also fully reflect the actual construction of shipping informationization, especially, meeting the requirement of information-based war. The standard specification of shipping informationization should not only link up with international and national technical standard specification and accurately reflect the development of new technology, but also fully consider the technological base and current of informationization, especially, how to 
comprehensively apply various systems in use to transform all kinds of information system at the best cost-effectiveness ratio.

In view of rapid development of information technology, the formulation of policies, regulations and standard specification of shipping informationization should be a certain forward-looking. At the same time, the construction of shipping informationization requests a long development process for realization, so the policies, regulations and standard specification relevant to shipping informationization needs some time to be established, enriched and perfected in practice, and also needs adequate psychological preparation.

C. In the construction of shipping informationization, the development trend and direction should be accurately grasped

Strengthening the construction of shipping informationization must be pulled by the needs of the future information-based society, based on the national information infrastructure, and view information technology as the main means of propulsion. When vigorously boosting the process of shipping informationization, the informationization should be regarded as a guide to improve the level of mechanization construction, to lead to a road of interaction between informationization and mechanization, as well as of leapfrog development with Chinese characteristics.

In recent years, the national investment in the shipping industry of China is no less than that of foreign famous peer enterprises, but is too dispersed. Each enterprise has a certain advantage in the research and development, but cannot complete the innovative development independently. So the human, financial and material resources existing in the state-owned enterprises should be integrated, so that they can generate a larger benefit. The construction of shipping informationization must be implemented, ensuring someone to promote it, someone to control it, someone to construct it, and someone to use it. Through strong organization and leadership, the construction of shipping informationization is organized to fully mobilize aspects of forces. The R\&D department and related forces are organized, and human, material and financial resources are concentrated, so as to actively promote the construction of shipping informationization, realizing the leap-forward development of modernization construction of shipping industry. As long as the shipbuilding enterprises grasp the trend and strategy of informationization development, they can effectively promote the informationization process indeed.

\section{Energetically cultivate high-quality talents in the field of informationization}

The talent is the basis of success for shipping informationization, is a fundamental element for the informationization of shipbuilding enterprises, has a decisive influence on the developing speed and quality of other informationization elements, and is the key to construct the informationization of shipbuilding enterprises.
Therefore, a high-quality talent team with reasonable structure in the research, development, production and application of informationization must be established, so as to adapt to the needs of construction of shipping informationization. The basic requirement for a high-quality informationization talent is to have a scientific mind and excellent information technical expertise. The cultivation of talent of shipping informationization includes the talents of information technical research and development, as well as the talents of informationization shipping management and security. Only the high-quality talents can give full play to the comprehensive advantages of shipping equipment, technology and procedure, and efficiently and stably boost the informationization construction of shipbuilding enterprises on the whole.

\section{REFERENCE MODEL FOR INFORMATIONIZATION PlatForm of SHIPPING PRODUCTION DESIGN}

On the basis of summarizing the predecessors' research results, the domestic shipbuilding enterprises introduce foreign advanced ideas and procedures of informationization construction step by step through longterm grope, improvement and innovation, and form the systematized shipbuilding informationization model and procedures in combination with China's national conditions and shipping enterprises' technology and management characteristics.

Taking the department of shipbuilding production design as an example, this paper provides the shipbuilding informationization procedure and a model for its information system in combination with the production manufacturing process. For a specific design task (after this system starts with contract design and detailed design), the system at first stores many drawings and documents from the designing institute, such as specifications, general layout, engine room arrangement plan, subsection division graph and equipment layout, and then all departments of production design refine the design drawings under the constraint of construction principles, construction essentials and manufacturability requirements read through the system, transform them into process drawings suitable for the manufacturing plant, including lofting, obtaining all kinds of engineering management chart, calculating the outfitting work chart and so on, and upload these technological documents to the database. The manufacturing department obtains process drawings through the system again for site construction, and records the information of components and middleware to be produced, knowledge information in the database. That is just a basic workflow, which will be modified according to specific situations in the implementation, as shown in Fig.1 Basic Workflow Diagram for Information-based Production Design (Hu Hao \&Guo Gang, 2009) 


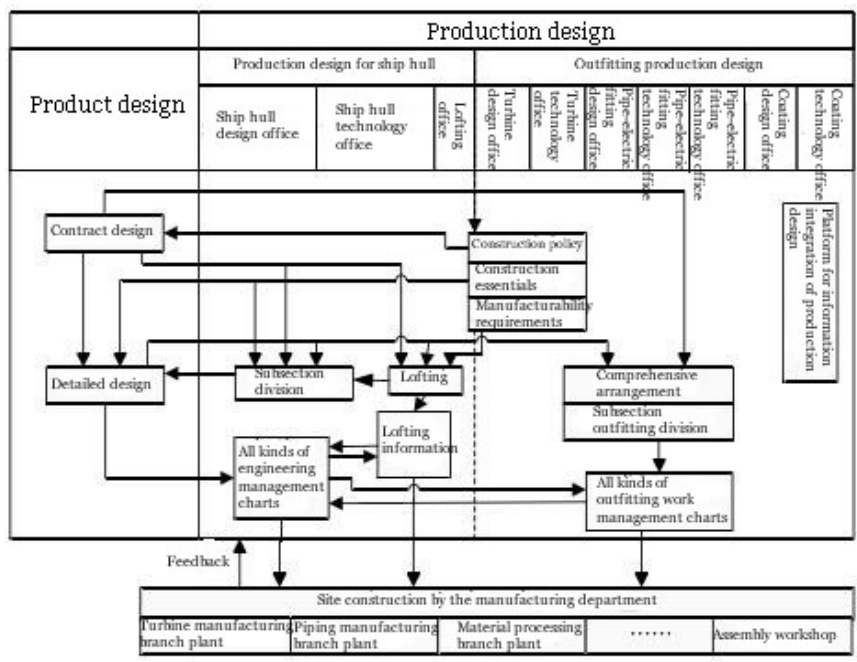

Figure 1 Basic Workflow Diagram for Information-based Production Design

The system model in Fig. 2 implements the advanced ideas of the top-level design and collaborative production from the systemic perspective, subsection in the aspect of space and having sequence in the aspect of time, to reflect two integrations, namely, "integration of turbine, ship hull and outfitting" and "integration of design, technology and management". The system has a guiding role in changing the current situation of informationization construction of many small and medium-sized shipbuilding factories in China, as shown in Fig. 2 Model for Information System of Shipping Production Design Department.

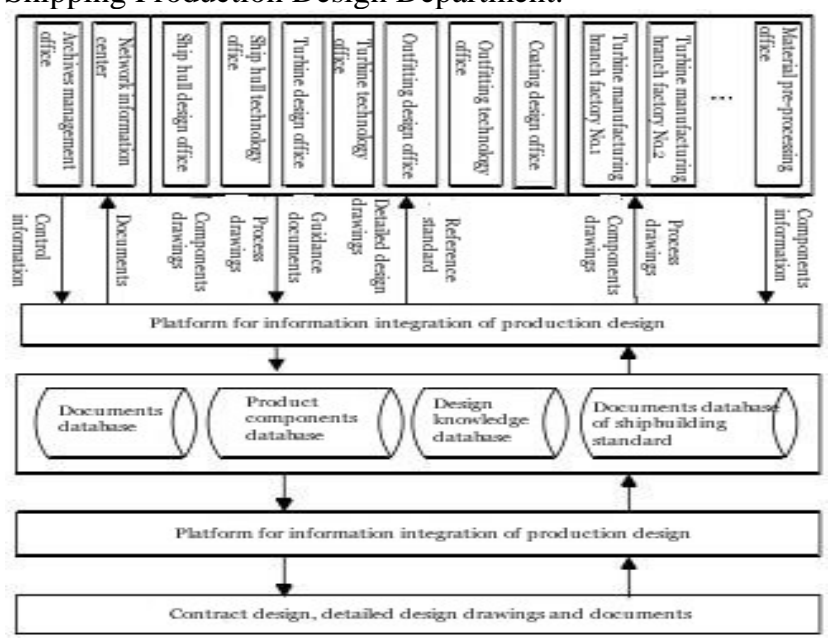

Fig. 2 shows us the workflow of production design on the platform for information integration of production design.

\section{VI.CONCLUSIONS}

Shipping enterprises belong to a final assembly-type enterprise, and their supply chain is more complicated. In the face of increasing market competition, as a capital, technology and labor-intensive industry, the shipbuilding industry must strengthen the construction of enterprise informationization, so as to maintain a certain advantages. From the products' purchase intention, product solution, quotation, contract and cooperative design to the products' delivery and after-sales service, each procedure must be negotiated, modified, fed back and confirmed repeatedly by the ship-owner, ship inspection organizations, shipbuilding factories, suppliers and so on. The information transfer of product cost, construction, cycle, quality, capital operation and other links directly affects the success or failure of ship products. Without efficient informationization means, the shipbuilding enterprises cannot survive. In combination of thinking analysis in this paper, the shipbuilding enterprises need to attach importance to the top-level design, policies and standards, talent cultivation and other important strategy and tactics links in the informationization construction; at the same time, they must realize that the construction of shipping informationization is a long-term complicated system engineering, the enterprises cannot to jump to success, and the construction must be combined with the current situation of enterprise informationization. First of all, the shipbuilding enterprises should make planning for information-based resources, and then use the informationbased platform to mobilize all the possible organizations, resources, technologies, talents, etc., pooling the wisdom and efforts of everyone, strengthen the basic management, optimize and reorganize the management process, improve the utilization rate of internal resources, and support the development of enterprises by means of informationization.

\section{REFERENCES}

[1] MA Dan, XIE Yiwu, LIU zheng, IRP Application in Information Construction of Ship Enterprise[J],China Ship Repair,2005(4):3-5

[2] HU Hao, GUO Gang;Study on system model of small and mediumsized enterprises's ship production design[J].Mechanics,2009(11):5860

[3] LI Guorui; Technology \& Development of main and auxiliary vessels[J],Shanghai Shipbuilding,2003(2):22-23

[4] WANG Qing; Information Technology is the Only Way to Ship Enterprises for Transformation Services[N/OL];China Ship News.2012-12-28

[5] LI YuBin; Information on ship construction Development Strategy[J],China Ship Repair,2004(6):3-6

[6] ZHENG Shijun, ZHU Jianxin, HUANG Aiping, HAN Chengmin, QIU Xinrao, XU Bo, Ship Management Information Research[J];Journal of Shanghai Maritime University,2002(2):14-17.

[7] XU Shaoheng; Information Technology Reform in Ship Automation Equipment,SHIP ENGINEERING,2010(5):37-39 